\title{
Post-thoracotomy pain and nerve protection: Back to the drawing board?
}

\author{
Scott I. Reznik, MD
}

From the University of Texas Southwestern Medical Center at Dallas, Dallas, Tex.

Disclosures: Author has nothing to disclose with regard to commercial support.

Received for publication Sept 24, 2018; accepted for publication Sept 26, 2018; available ahead of print Nov 7, 2018

Address for reprints: Scott I. Reznik, MD, 5323 Harry Hines Blvd, MC 8879, Dallas, TX 75390-8879 (E-mail: scott.reznik@utsouthwestern.edu).

J Thorac Cardiovasc Surg 2019;157:376-7

$0022-5223 / \$ 36.00$

Copyright (C) 2018 by The American Association for Thoracic Surgery

https://doi.org/10.1016/j.jtcvs.2018.09.099

Jiwnani and colleagues ${ }^{1}$ present a randomized, doubleblinded trial of conventional versus nerve-sparing thoracotomy. Acute and chronic pain after thoracotomy can lead to significant morbidity, especially pulmonary complications, and has been one of the main drivers of minimally invasive techniques in thoracic surgery. Many investigators have reported improvement in postoperative pain by using nerve-sparing techniques, such as intercostal suturing, edge-to-edge sutures, and protection of the intercostal nerve by mobilizing the intercostal bundle., ${ }^{2,3}$ Nerve-sparing techniques are attractive, because they are straightforward, quick, and associated with low operative costs. Several studies have reported decreased pain, whereas others have found no difference. ${ }^{4-7}$

Should this trial signal the end of nerve-sparing thoracotomy techniques? The answer is unclear. The average and maximum pain scores are relatively low in both the control and treatment groups, 1.85 and 3.83 versus 1.77 and 3.71 , respectively. ${ }^{1}$ More representative of what many see after a thoracotomy was reported in an Italian study: average pain scores on postoperative day 1 of 6.2 and 4.3 in the standard and intervention groups, respectively. ${ }^{5}$ Study design could be an issue. This study was powered to detect a 1-point decrement between the control and treatment arms of the study. Whether that is an appropriate target or not is debatable. It may be unrealistic to expect that any intervention would decrease the maximum perceived pain by $25 \%$ and average pain by $50 \%$. A larger sample size might detect a smaller change in pain, but would this change be clinically relevant? The authors state no. However, in another nerve-sparing study, Allama ${ }^{4}$ reported the differences in immediate mean pain scores ranged from 0.25 to 0.43 on the 10-point scale between treatment groups and reported less analgesic use and earlier return to daily activities. Perceptions of pain may be related to cultural factors and provider and patient

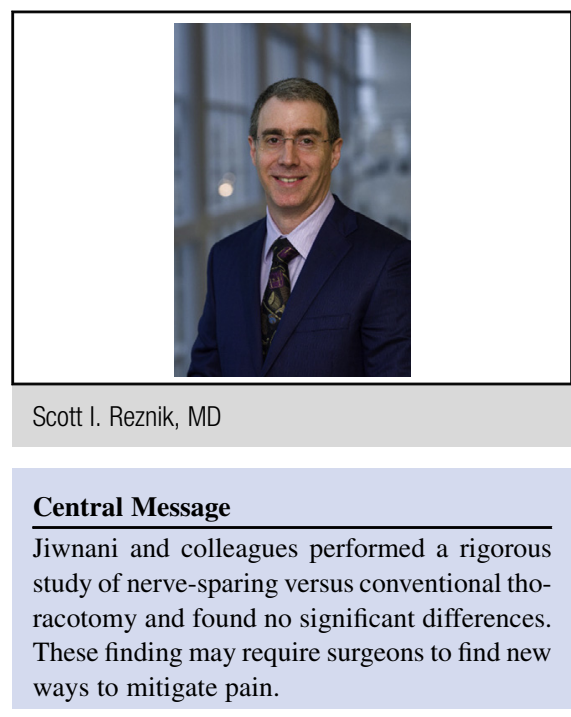

See Article page 380.

expectations. Factors associated with increased thoracotomy pain include the degree and duration of rib spreading, type of retractor used, tissue-handling technique, and perioperative and intraoperative pain management. Patient factors can influence pain, such as preexisting conditions (controlled for in this study) or body mass index. The body mass indices in this study were 21.7 and $23.0 \mathrm{~kg} / \mathrm{m}^{2}$ for the study and control groups, respectively. This morphology would not be typical in North American populations. Conversely, when minimally invasive techniques are the standard, thoracotomy is reserved for emergencies or patients with extensive pathology and require more access through rapid or wider rib spreading. The authors did report incidental rib fractures, which may be considered a surrogate for rapid or excessive rib spreading, mitigating this as a confounding variable.

Do we surgeons need to go back to the drawing board and find new ways to mitigate pain from an incision that cannot be abandoned? Emphatically yes. Did Jiwnani and colleagues ${ }^{1}$ close the book on nerve-sparing thoracotomy? Not yet. Clearly, there was little difference in outcomes between the control and experimental groups. This well-controlled and carefully analyzed study should encourage us to keep searching.

\section{References}

1. Jiwnani S, Ranganathan P, Patil V, Agarwal V, Karimundackal G, Pramesh CS Pain after posterolateral versus nerve-sparing thoracotomy: a randomized trial. $J$ Thorac Cardiovasc Surg. 2019;157:380-6. 
2. Cerfolio RJ, Bryant AS, Maniscalco LM. A nondivided intercostal muscle flap further reduces pain of thoracotomy: a prospective randomized trial. Ann Thorac Surg. 2008;85:1901-7.

3. Cerfolio RJ, Bryant AS, Patel B, Bartolucci AA. Intercostal muscle flap reduces the pain of thoracotomy: a prospective randomized trial. J Thorac Cardiovasc Surg. 2005;130:987-93.

4. Allama AM. Intercostal muscle flap for decreasing pain after thoracotomy: a prospective randomized trial. Ann Thorac Surg. 2010;89:195-9.

5. Ibrahim M, Menna C, Andreetti C, Puyo C, Maurizi G, D'Andrilli A, et al. Does a multimodal no-compression suture technique of the intercostal space reduce chronic postthoracotomy pain? A prospective randomized study. J Thorac Oncol. 2016;11:1460-8.

6. Montazer M, Hashemzade S, Gargari RM, Ramouz A, Sanaie S, Rasihashemi SZ. Combination of intracostal sutures with muscle flap to decrease post thoracotomy pain: a single blinded randomized clinical trial. Pak J Med Sci. 2017;33:42-7.

7. Wu N, Yan S, Wang X, Lv C, Wang J, Zheng Q, et al. A prospective, single-blind randomised study on the effect of intercostal nerve protection on early post-thoracotomy pain relief. Eur J Cardiothorac Surg. 2010;37: $840-5$. 